\title{
Critical Analysis of Esophageal Multichannel Intraluminal Impedance Monitoring 20 Years Later
}

\author{
Fernando A. M. Herbella ${ }^{1,2}$ \\ ${ }^{1}$ Department of Surgery, São Paulo Medical School, Federal University of São Paulo, 04021-001 São Paulo, SP, Brazil \\ ${ }^{2}$ Surgical Gastroenterology, Division of Esophagus and Stomach, Hospital São Paulo, Rua Diogo de Faria 1087 cj 301, \\ 04037-003 São Paulo, SP, Brazil
}

Correspondence should be addressed to Fernando A. M. Herbella, herbella.dcir@epm.br

Received 29 July 2012; Accepted 13 September 2012

Academic Editors: G. H. Kang, A. Nakajima, and C.-T. Shun

Copyright (C) 2012 Fernando A. M. Herbella. This is an open access article distributed under the Creative Commons Attribution License, which permits unrestricted use, distribution, and reproduction in any medium, provided the original work is properly cited.

Multichannel intraluminal impedance (MII) for the evaluation of esophageal diseases was created in 1991 trying to solve previous limitations of esophageal function test. MII-pH is able to determine the physical characteristics of the refluxate (liquid, gas, or mixed) and nonacidic GER. MII-manometry can determine the presence of bolus and its relation with peristalsis. This paper makes a critical analysis of the clinical applications of MII 20 years after its creation. Literature review shows that MII made great contributions for the understanding of esophageal physiology; however, direct clinical applications are few. MII-pH was expected to identify patients with normal acid reflux and abnormal nonacidic reflux. These patients are rarely found off therapy, that is, nonacidic reflux parallels acid reflux. Furthermore, the significance of isolated nonacidic reflux is unclear. Contradictory MIImanometry and conventional manometry findings lack better understanding and clinical implication as well as the real significance of bolus transit.

\section{Introduction}

Esophageal manometry and $\mathrm{pH}$ monitoring are ambulatory techniques for detection of gastroesophageal reflux (GER) and esophageal motility disorders that were introduced into clinical practice in the 1970s; however, significant improvement was achieved over the last decades [1], including the development of multichannel intraluminal impedance (MII) in 1991 [2]. These new achievements try to solve previous limitations of esophageal function test, such as the lack of ability to detect bolus transit and nonacid reflux.

A great enthusiasm came when MII was applied to esophageal physiology. First of all, the expectation that patients with suspected GER and a negative $\mathrm{pH}$ monitoring would have the disease objectively diagnosed came into mind. Second, the detection of bolus transport through the esophagus brought hope to the treatment of patients with dysphagia and normal manometry. This initial enthusiasm; however, subsided along time. This paper will focus on the critical analysis of the clinical applications of MII, 20 years after its creation.

\section{MII Technique}

Impedance is the measurement in Ohms of the electrical resistance between 2 points. In simple words, 2 consecutive sensors are in contact with the esophageal mucosa that has specific impedance value, but when the lumen is filled with any substance and this substance bridges these 2 sensors, the equipment will detect this variance. Because of their differential conductivity, gas, liquid, or a mixture of the two can be distinguished independent of the $\mathrm{pH}$ of the material. The order in which the sensor detects the material also allows determining the direction of its flow. The passage of liquid substances between the sensors decreases the impedance value. It is detected as a drop in the impedance of more than $50 \%$ from the baseline. In contrast, gas has high electrical resistance, leading to an increase in impedance of more than $50 \%$ the baseline, or an absolute value $>7,000$ ohms and mix of gas and liquid will be a combination of both. Return to $50 \%$ of the baseline is considered the end of the episode. During deglutition, lumen substances are detected first in the most proximal sensors and then progresses distally. A reflux 


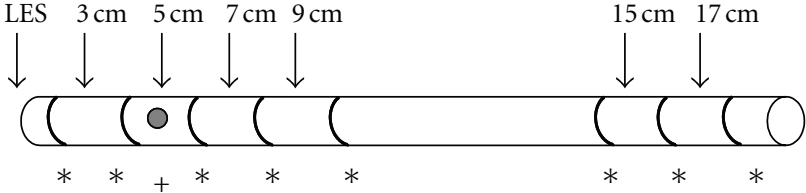

Figure 1: Multichannel Intraluminal Impedance and $\mathrm{pH}$ monitoring catheter. $*$-impedance sensors, $+-\mathrm{pH}$ sensors, and LES-lower esophageal sphincter.

episode is considered when lumen substances are detected first in distal sensors and then propagates aborally in at least two proximal sensors. Simultaneous detection of an episode of reflux by the $\mathrm{pH}$ sensor and by the impedance sensors denotes an acid reflux. Detection of an episode of reflux only by the impedance sensors denotes a non-acid reflux $[3,4]$.

MII-pH is a catheter-based technology. It consists of a catheter comparable to the conventional $\mathrm{pH}$-monitoring where antimony sensors are similarly used to detect $\mathrm{pH}$, but impedance sensors are also displaced in the catheter. The arrangement of the sensors is variable according to the manufacturer; however, the most common placement is shown in Figure 1.

Baseline measurement of impedance levels may denote mucosal integrity $[4,5]$ although its clinical significance is still elusive.

\section{Assessment of Gastroesophageal Reflux}

Conventional catheter-based prolonged ambulatory esophageal $\mathrm{pH}$ monitoring has been used since the 1970s. Its usefulness in clinical practice and research has been proven and reassured along time [6].

The first attempt to detect GER was accomplished in 1884 by Reichman, who lowered a sponge into the esophagus of a patient with heartburn and showed that it contained acid when retrieved. Over 50 years later, Aylwin in 1953 found acid and pepsin in the esophageal juice-retrieved with the aid of a tube - of patients with esophagitis [1]. The first in situ measurement of acid reflux in the esophagus is credited to Tuttle and Grossman in 1958 who used equipment previously described to study gastric $\mathrm{pH}$ and combined it with esophageal manometry. They studied different probe positions and $\mathrm{pH}$ levels and ultimately concluded that acid drop below 3 at $2 \mathrm{~cm}$ proximal to the respiratory inversion point was indicative of acid reflux [7]. Many other studies on the subject followed. Initially, recording machines were not portable, forcing patients to be wired to large equipments, making the procedure an in-patient system [1]. Radiofrequency transmission of $\mathrm{pH}$ data is not a modern technology; in fact its development started in the 1950s, and it was almost parallel to the "conventional" catheter technique. However, state-of-the-art technology for catheterfree wireless $\mathrm{pH}$ sensors and a new technology to attach the capsule were introduced in 2001 [8].

Detection of intraluminal esophageal impedance was developed in the early 1990s [2]. The combination of simultaneous detection of esophageal acidity $(\mathrm{pH})$ and
impedance-MII was also a landmark in understanding and evaluating GER.

Gastric and duodenal contents both can reflux into the esophagus and adjacent organs. Gastric hydrochloric acid has long been recognized as harmful to the esophagus [9]. Currently, it is recognized that bile reflux is also noxious to the esophagus [10].

Detection of non-acidic has been tried for decades. Researchers were motivated by patients with clinical and endoscopic evidence of GER but normal $\mathrm{pH}$ monitoring $[11,12]$, when non-acid reflux was suspected as the etiology of symptoms and mucosal damage in these patients $[13,14]$ since bile-induced esophagtis en experimental models [15, 16]. Different methods have been developed to detect nonacidic reflux, such as: esophageal intubation and aspiration [17-19], detection of bile in the sputum [20, 21], alkaline $\mathrm{pH}$ shift at the $\mathrm{pH}$ monitoring $[22,23]$, and scintigraphy [24]. All described methods did not prove useful due to technical limitations, low sensitivity, nonphysiologic situations, and nonprolonged measurements. Probably the most promising technology was bilirubin monitoring through spectrophotometry (Bilitec 2000). It consists of a portable sensor coupled to a $\mathrm{pH}$ sensor in the tip of a catheter. It allows ambulatory measuring similar do conventional $\mathrm{pH}$ monitoring [25].

MII-pH goes further than the previous technologies and it is also able to determine the physical characteristics of the refluxate (liquid, gas, or mixed) and non-acidic GER [26, 27].

New concepts became evident only after the advent of MII-pH. For instance, rereflux (or superimposed reflux) is characterized by reflux episodes detected at impedance in a background $\mathrm{pH}<4$ after the initialization of a primary reflux event [28]. It seems to be associated to patients with severe esophagitis, postprandially, and in the recumbent posture [29]; however, its clinical relevance must be clarified.

Also, the correlation between symptoms and the $\mathrm{pH}$ of the refluxate have been studied. It was demonstrated that MII-pH improves the sensibility to correlate symptoms with episodes of reflux, since a significant number of symptoms may occur during non-acid episodes [30]. Various studies showed that heartburn is more commonly experienced in acid reflux [31-33], while regurgitation [31,32] and cough $[33,34]$ are symptoms most associated to non-acid reflux.

Different publications studied the effect of antisecretory drugs on the composition of GER. Their results, either studying volunteers [35] or patients [32], showed that the number and duration of reflux episodes were not changed by proton pump inhibitors, only the $\mathrm{pH}$ of the refluxate.

$\mathrm{MMI}-\mathrm{pH}$, different from conventional $\mathrm{pH}$ monitoring, can discriminate the physical characteristics of the refluxate (liquid, gas, or mixed). The clinical importance of this characteristic is still elusive. Tutuian et al. [36] have shown that reflux episodes that were associated with symptoms in patients who failed clinical therapy were primarily composed of both gas and liquid. Emerenziani et al. [37] showed that in heartburn patients the risk of reflux perception was significantly higher when gas was present in the refluxate. On the other side, mixed reflux (gas + liquids) comprises half of the episodes of reflux in volunteers $[37,38]$ and patients with 
erosive GER, nonerosive GER, and healthy individuals have the same amount of gas containing episodes of reflux [38, 39]. Both surgical [40] and clinical [37] therapy decreases the number of gas-containing reflux episodes; however, it is unclear if symptomatic relieve is linked to this finding since other forms of refluxate are also controlled by these therapies.

\section{Critical Analysis of MII-pH}

Previous methods to detect non-acid reflux (Bilitec, esophageal aspiration, scintigraphy, etc.) were contributory; however, technical limitations precluded widespread use of the technology. Even though, they made great contributions for the understanding of gastroesophageal reflux disease and esophageal physiology. MII-pH is probably the most effective method to detect non-acid reflux.

The aforementioned characteristics of the MMI-pH technology also brought great contribution for the understanding of gastroesophageal reflux disease and esophageal physiology. Clinical implications are; however, limited by: (1) studies with controversial results, (2) the rarity of isolated alkaline reflux, and (3) the lack of clinical implication on prognosis, therapeutic decision or postoperative evaluation.

The prevalence of weak-acidic GER (esophageal pH 47 + reflux detected at he MII) is variable in different series. Weakly acidic reflux ranges from 20 to $66 \%$ of the episodes of GER in healthy individuals $[26,41,42]$. In GER patients, weakly acidic GER shows no higher percentage-30-70\% [43-45]. The reasons for the difference in prevalence of weakly acidic reflux between studies are unclear and require further investigation. Ambulatory impedance $\mathrm{pH}$ studies suggest that patients with moderate and severe esophagitis have rates of weakly acidic reflux similar to or slightly greater than healthy controls. Furthermore, distal esophageal exposure to weakly acidic refluxate is similar in esophagitis and nonerosive reflux disease (NERD) patients [46]. Also, the composition of the refluxate must be better clarified. Weakly acidic reflux is more likely to occur early after a meal, both in controls and in patients with reflux disease [47]. Studies using $\mathrm{pH}-\mathrm{Bilitec}$ recordings have shown that most bile reflux events occur in an acid setting, with esophageal pH below 4 [48]. It is possible that differences in mixing and distribution of postprandial gastric contents might explain the occurrence of either weakly acidic reflux with little or no biliopancreatic secretion [47]. If patients with abnormal weakly acidic reflux and physiologic acid reflux can be classified as refluxers is a question to be answered. Alkaline reflux $(\mathrm{pH}>7)$ is a rare event $[26,41,42]$.

MII-pH has not showed to be useful to predict treatment response. Bredenoord et al. [40] showed that MII parameters for non-acid reflux (symptom association or number of episodes of reflux) are not predictive for response to protonpump inhibitors in GER patients. Similarly, MII parameters do not predict outcomes after antireflux surgery (fundoplication) $[49,50]$. On therapy MII-pH is a common method for the detection of the persistence of GER in patients refractory to pharmacologic therapeutic [51]. Although we honestly believe that for patients with proven GER off therapy, this evaluation is unnecessary.

MII-pH has not shown to be useful in the postoperative period of antireflux operation (fundoplication). Arnold et al. [52] showed that in asymptomatic patients with a negative $\mathrm{pH}$ monitoring, the rate of false positive MII-pH of $50 \%$ renders the test clinically irrelevant. This may explain findings such as a lack of decrease in nonacid reflux episodes after endoscopic fundoplication as it is not selective to the type of refluxate [53].

Further considerations are necessary. Catheter-based esophageal function tests are nonphysiologic methods. One of the reasons appointed to a false-negative $\mathrm{pH}$ monitoring is alteration in normal life style, food intake, and hypersalivation due to the presence of the transnasal catheter. Wireless catheter-free implantable capsule-based $\mathrm{pH}$-monitoring was created to prevent the discomfort associated to the presence of the esophagonasal catheter $[54,55]$. Unfortunately, untoward effects and limitations are frequent, most of them related to the fixation method that pins the capsule to the esophageal mucosa. Thus, problems reported are: (1) the capsule fails to deploy and attach to the esophageal mucosa in a significant percentage of patients (ranging from 0.5 to $20 \%$ [56-60]); (2) the presence of the capsule in the esophagus may cause symptoms. The majority of patients experience foreign body sensation, especially with swallow and dysphagia $[56,60,61]$. Chest pain occurs in $33-50 \%$ of patients previously free of this symptom $[58,59]$. The pain may be severe in 1 to $9 \%$ of the patients and removal of the capsule may be occasionally necessary in 2 to $5 \%$ of the patients, from 1 hour up to 5 days after the procedure [61]. Nausea was also reported in $6 \%$ of the studies [58]; (3) in a significant number of studies (2 to $12 \%[56,57,60]$ ) data cannot be completely retrieved. Reasons for incomplete data retrieval are unexplainable failure of the device (either the capsule or the receiver), interference due to other wireless devices, permanence of the receiver to far from the patient, and detachment of the capsule. The capsule is designed to detach in 3-7 days and be expelled in the stool. Premature detachment of the capsule can occur in 2 to $5.5 \%$ of the cases $[56,57,59,60] ;$ (4) in the opposite direction, nondetachment of the capsule after 15 days requiring endoscopic removal was reported [61]; (5) the number of reflux episodes are consistently lower when Bravo capsule is compared to conventional $\mathrm{pH}$ monitoring [59]. This is credited to the lower sampling rate (every 6.25 seconds, compared to 4 per second) of the Bravo system [62], fixed position of the wireless capsule that prevents it to dip inside the stomach during swallows [63], and inaccuracy in calibration of the capsule [64]; and (6) a precise positioning based on the LES can be accomplished using Bravo system if manometry is done previously and transnasal route is used to place the capsule. However, the squamous-columnar transition, a variable anatomical position, is utilized as landmark if the transoral route is used. Currently, there is no system able to measure nonacid reflux through a wireless capsule. Other point is a prolonged (more than 1 day) measurement of GER. Different studies showed that increasing the period of analysis increases the sensitivity for GER detection $[55,65$, $66]$. 


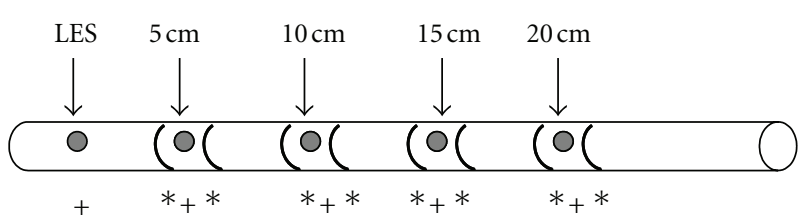

Figure 2: Multichannel intraluminal impedance and esophageal manometry catheter. $*$-impedance sensors, +- manometry sensors, and LES-lower esophageal sphincter.

\section{Assessment of Esophageal Motility}

The same technology for MII-pH has been used in combination with esophageal manometry. MII-manometry can determine the presence of bolus and its relation with peristalsis. Analysis of MII-manometry is very similar to the analysis of MII-pH. Transit of the bolus induces the same pattern of impedance measurement.

Similarly to MII-pH, impedance sensors are also displaced along a conventional manometry catheter. Both water perfused [32] and solid state [28] catheters can be used, although the former is more common. The arrangement of the sensors is variable according to the manufacturer; however, the most common format is shown in Figure 2.

Analysis of MII-EM tracings is very similar to the analysis of MII-pH. Transit of the bolus induces the same pattern of impedance measurement. Usually, 10 viscous swallows, not only 10 liquid swallows, are usually added to the analysis [67] allowing higher detection of esophageal function defects compared to liquid swallows [68]. Obviously, the addition of viscous swallows can be integrated to the conventional manometry as well [69]. More recently, solid swallows have also been added to MII [70]. Multiple parameters can be recorded; nevertheless bolus clearance and transit time are simple but informative parameters (Figure 3 ). This technology allows (1) monitoring of bolus transport patterns, (2) calculation of bolus transit parameters, (3) evaluation of bolus clearance, (4) monitoring of swallow associated events such as air movement and reflux, and (5) investigation of the relationships between bolus transit and LES relaxation [71].

Tutuian and Castell [72] studying 350 patients with a wide range of esophageal diseases reported that complete bolus transit detected with the impedance was identified in $96 \%$ of manometric normal swallows, $33 \%$ of ineffective, and $53 \%$ of simultaneous waves considering liquids swallows. Furthermore, distal esophageal amplitude was higher in patients with complete bolus clearance, as expected.

Different motility disorders have been studied by MIImanometry. Published studies showed that patients with achalasia and scleroderma have always abnormal bolus transit [72-74]. Almost half of patients with ineffective esophageal motility and diffuse esophageal spasm have normal bolus transit, while almost all patients with normal esophageal manometry, nutcracker esophagus, poor relaxing LES, hypertensive LES, and hypotensive LES have normal bolus transit $[72,74]$. The analysis of these results according to subgroups of diseases, not only reinforces some previous

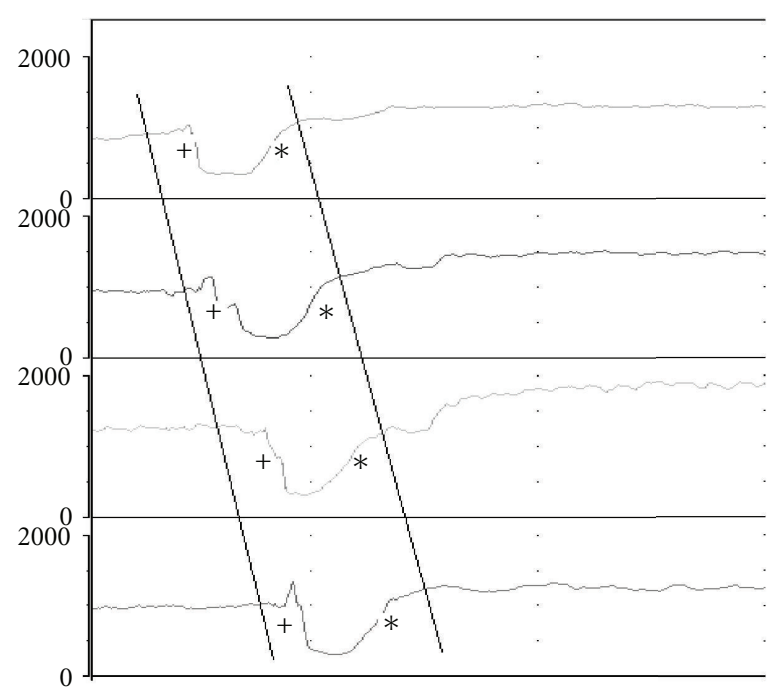

FIGURE 3: Impedance parameters in the multichannel intraluminal impedance and esophageal manometry. Bolus clearance is complete if bolus is detected at the most proximal sensor and it "exits" all sensors in sequence, as shown in the figure. Bolus transit time is the period of time between the first and the last detection of the bolus, in the most proximal and in the most distal sensor, respectively. +begin of bolus detection and $*$-end of bolus detection.

concepts but also changes some of them. Esophageal motility abnormalities can be classified as transit defect or pressure defect [75]. Some conclusions are: (a) achalasia and scleroderma are associated to manometric abnormalities and abnormal bolus transit, as expect; (b) isolated sphincter abnormalities do not affect bolus transit; (c) ineffective esophageal motility may have a normal bolus clearance; (d) diffuse esophageal spasm may have a normal bolus clearance; (f) nutcracker esophagus is a disease of abnormal pressures, not abnormal bolus transit; and (g) abnormal bolus clearance can be seen in a small number of patients with normal manometry.

MII role in the workup for belching disorders and rumination seems promising [76].

\section{Critical Analysis of MII-Manometry}

Similarly to MII-pH, MII-manometry made great contributions for the understanding of esophageal physiology; however, direct clinical application is jeopardized by 3 points: (1) different MII findings are found in the same series of patients; (2) abnormal MII findings did not prove a real value in changing current treatment options; (3) MIImanometry does not predict treatment outcomes; and (4) the significance of discrepant MII and manometry results is elusive.

A percentage of altered and normal MII has been reported in healthy volunteers [55], patients with dysphagia and without dysphagia $[77,78]$, and patients in the postoperative of Nissen fundoplication with and without dysphagia [79]. Bogte et al. [80] affirmed that stasis of both liquid and 


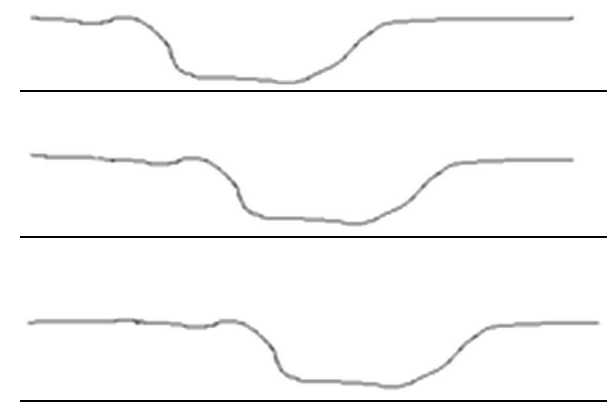

(a)

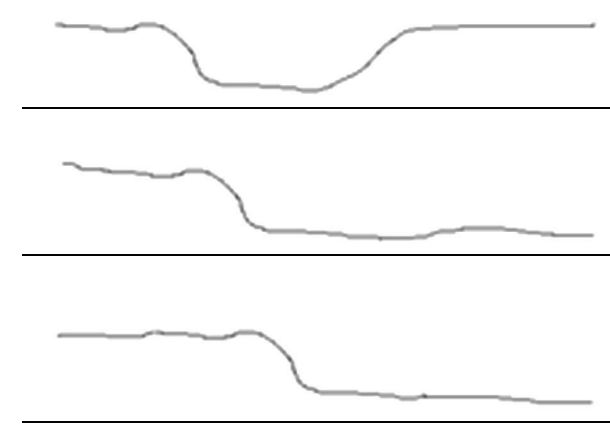

(c)

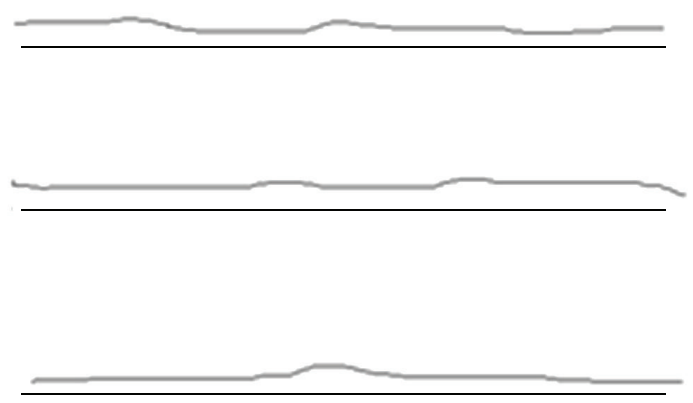

(b)

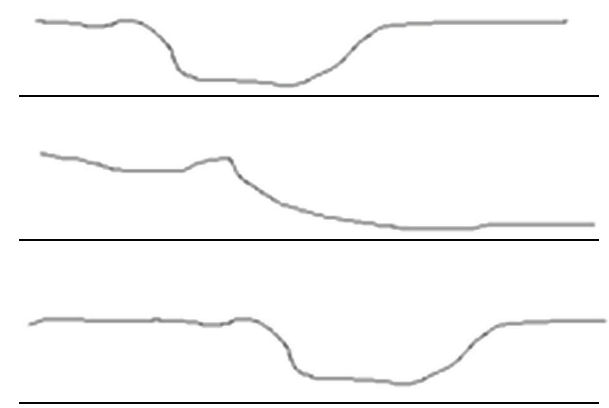

(d)

Figure 4: Multichannel intraluminal impedance (MII) patterns for bolus transport. (a) Normal bolus transport. A decrease in basal impedance measurement and subsequent return to basal levels is noticed in all channels (proximal, medium, and distal). (b) Abnormal bolus transport. All channels display a low basal impedance level unchanged by swallow. This may be explained by fluid repletion of the esophagus? It is a common pattern in achalasia patients. (c) Abnormal bolus transport. The proximal channel shows a normal bolus propagation. More distal channels display a retention of the bolus distally. This may be explained by outflow resistance at the esophagogastric junction. (d) Abnormal bolus transport. Retention of the bolus is noticed in the midesophagus. This may be explained by segmental aperistalsis.

solid boluses occurs frequently in patients and in controls and can be regarded as physiological!

Classically, esophageal motility disorders have been classified, named, and treated based on manometric characteristics [81]. The recent advent of high-resolution manometry allowed the development of a different classification [82] but again with direct clinical implications for treatment $[83,84]$. Moreover, MII have been recently coupled with high-resolution manometry [85-89], interestingly; however, MII proved to validate high-resolution manometry ability to detect bolus transport and not the opposite $[89,90]$. No MIIspecific patterns were identified in order to create dysmotility classifications. Also, the lack of correlation between symptom (dysphagia) and abnormal bolus transit increases the confusion to understand MII-manometry findings [91, 92]. Furthermore, low baseline impedance levels, air entrapment and erratic liquids movement in the esophagus limit the application of MII in achalasia and other motility disorders with serious impairment of esophageal clearance $[3,6,93]$ (Figure 4).

MII-manometry did not show to be useful to predict dysphagia after antireflux operations [78]. Impaired flow through the esophagogastric junction may lead to dysphagia after fundoplication, however, this finding correlates with conventional manometric findings [94].
The combination of impedance and esophageal manometry allowed the identification of 4 patterns of swallows: (1) peristaltic waves (based on manometry) and bolus cleared (based on MII); (2) peristaltic waves without bolus clearance; (3) nonperistaltic or ineffective waves and bolus cleared; and (4) nonperistaltic or ineffective waves without bolus clearance. It is intuitive to understand and explain the concordance of MII and manometry findings represented by previous items (1) and (4). The understanding of items (3) and (4) boggles the mind to explain how bolus transit and muscular contraction are disconnected.

\section{Conclusions}

MII made great contributions for the understanding of esophageal physiology; however, direct clinical applications are few.

MII-pH was expected to identify patients with normal acid reflux and abnormal nonacidic reflux. Unfortunately, these patients are rarely found off therapy, that is, nonacidic reflux parallels acid reflux [95]; and the significance of isolated nonacidic reflux is unclear [1]. Repeating words by Sifrim and Zerbib [96]: "Combined $\mathrm{pH}$-impedance has little added value in patients 'off' therapy and virtually no outcome data exist to determine the optimal $\mathrm{pH}$-impedance parameters." 
The significance of bolus transit is elusive. MIImanometry findings that contradicts manometry lacks better understanding and clinical implication.

Future technologies may fill these clinical expectancies. Molecular imprinting technology with biosensors to detect bile [97], an implantable, wireless, and batteryless impedance sensor capsule that infers impedance based on a direct measurement of capacitance and receives energy from an external source [98], and intraluminal miniultrasound [99] are examples in development.

\section{References}

[1] F. A. M. Herbella, I. Nipominick, and M. G. Patti, "From sponges to capsules. The history of esophageal $\mathrm{pH}$ monitoring," Diseases of the Esophagus, vol. 22, no. 2, pp. 99-103, 2009.

[2] J. Silny, "Intraluminal multiple electric impedance procedure for measurement of gastrointestinal motility," Journal of Gastrointestinal Motility, vol. 3, no. 3, pp. 151-162, 1991.

[3] F. A. M. Herbella and J. C. Del Grande, "New ambulatory techniques for assessment of esophageal motility and their applicability on achalasia study," Revista do Colegio Brasileiro de Cirurgioes, vol. 35, no. 3, pp. 199-202, 2008.

[4] R. Farré, K. Blondeau, D. Clement et al., "Evaluation of oesophageal mucosa integrity by the intraluminal impedance technique," Gut, vol. 60, no. 7, pp. 885-892, 2011.

[5] B. F. Kessing, A. J. Bredenoord, P. W. Weijenborg, G. J. Hemmink, C. M. Loots, and A. J. Smout, "Esophageal acid exposure decreases intraluminal baseline impedance levels," The American Journal of Gastroenterology, vol. 106, no. 12, pp. 2093-2097, 2011.

[6] P. M. Fisichella and M. G. Patti, "The evolution of oesophageal function testing and its clinical applications in the management of patients with oesophageal disorders," Digestive and Liver Disease, vol. 41, no. 9, pp. 626-629, 2009.

[7] S. G. Tuttle and M. I. Grossman, "Detection of gastroesophageal reflux by simultaneous measurement of intraluminal pressure and $\mathrm{pH}$," Proceedings of the Society for Experimental Biology and Medicine, vol. 98, pp. 225-227, 1958.

[8] S. Ayazi, J. C. Lipham, G. Portale et al., "Bravo catheterfree $\mathrm{pH}$ monitoring: normal values, concordance, optimal diagnostic thresholds, and accuracy," Clinical Gastroenterology and Hepatology, vol. 7, no. 1, pp. 60-67, 2009.

[9] H. Quincke, "Ulcus oesophagis ex digestione," Deutsches Archiv für Klinische Medicin, vol. 24, pp. 72-79, 1879.

[10] F. A. Herbella and M. G. Patti, "Gastroesophageal reflux disease: from pathophysiology to treatment," World Journal of Gastroenterology, vol. 16, no. 30, pp. 3745-3749, 2010.

[11] G. C. Vitale, W. G. Cheadle, S. Sadek, M. E. Michel, and A. Cuschieri, "Computerized 24-hour ambulatory esophageal $\mathrm{pH}$ monitoring and esophagogastroduodenoscopy in the reflux patient. A comparative study," Annals of Surgery, vol. 200, no. 6, pp. 724-728, 1984.

[12] M. G. Patti, U. Diener, A. Tamburini, D. Molena, and L. W. Way, "Role of esophageal function tests in diagnosis of gastroesophageal reflux disease," Digestive Diseases and Sciences, vol. 46, no. 3, pp. 597-602, 2001.

[13] C. Cortesini, G. Marcuzzo, and F. Pucciani, "Relationship between mixed acid-alkaline gastroesophageal reflux and esophagitis," Italian Journal of Surgical Sciences, vol. 15, no. 1, pp. 9-15, 1985.
[14] D. L. Stoker and J. G. Williams, "Alkaline reflux oesophagitis," Gut, vol. 32, no. 10, pp. 1090-1092, 1991.

[15] J. A. Salo and E. Kivilaakso, "Contribution of trypsin and cholate to the pathogenesis of experimental alkaline reflex esophagitis," Scandinavian Journal of Gastroenterology, vol. 19, no. 7, pp. 875-881, 1984.

[16] K. D. Lillemoe, L. F. Johnson, and J. W. Harmon, "Alkaline esophagitis: a comparison of the ability of components of gastroduodenal contents to injure the rabbit esophagus," Gastroenterology, vol. 85, no. 3, pp. 621-628, 1983.

[17] A. Pauwels, A. Decraene, K. Blondeau et al., "Bile acids in sputum and increased airway inflammation in patients with cystic fibrosis," Chest, vol. 141, no. 6, pp. 1568-1574, 2012.

[18] D. C. Gotley, A. P. Morgan, and M. J. Cooper, "Bile acid concentrations in the refluxate of patients with reflux oesophagitis," British Journal of Surgery, vol. 75, no. 6, pp. 587590, 1988.

[19] F. Johnsson, B. Joelsson, C. H. Floren, and A. Nilsson, "Bile salts in the esophagus of patients with esophagitis," Scandinavian Journal of Gastroenterology, vol. 23, no. 6, pp. 712-716, 1988.

[20] M. Grabowski, A. Kasran, S. Seys et al., "Pepsin and bile acids in induced sputum of chronic cough patients," Respiratory Medicine, vol. 105, no. 8, pp. 1257-1261, 2011.

[21] F. Stipa, H. J. Stein, H. Feussner, S. Kraemer, and J. R. Siewert, "Assessment of non-acid esophageal reflux: comparison between long-term reflux aspiration test and fiberoptic bilirubin monitoring," Diseases of the Esophagus, vol. 10, no. 1, pp. 24-28, 1997.

[22] S. Mattioli, V. Pilotti, V. Felice et al., "Ambulatory 24-hr $\mathrm{pH}$ monitoring of esophagus, fundus, and antrum. A new technique for simultaneous study of gastroesophageal and duodenogastric reflux," Digestive Diseases and Sciences, vol. 35, no. 8, pp. 929-938, 1990.

[23] A. G. Little, E. I. Martinez, T. R. DeMeester, R. M. Blough, and D. B. Skinner, "Duodenogastric reflux and reflux esophagitis," Surgery, vol. 96, no. 2, pp. 447-454, 1984.

[24] M. Tuncel, P. O. Kiratll, T. Aksoy, and M. F. Bozkurt, "Gastroesophageal reflux scintigraphy: interpretation methods and inter-reader agreement," World Journal of Pediatrics, vol. 7, no. 3, pp. 245-249, 2011.

[25] M. Dolder and R. Tutuian, "Laboratory based investigations for diagnosing gastroesophageal reflux disease," Best Practice and Research, vol. 24, no. 6, pp. 787-798, 2010.

[26] B. K. Oelschlager, E. Quiroga, J. A. Isch, and F. CuencaAbente, "Gastroesophageal and pharyngeal reflux detection using impedance and 24-hour $\mathrm{pH}$ monitoring in asymptomatic subjects: defining the normal environment," Journal of Gastrointestinal Surgery, vol. 10, no. 1, pp. 54-62, 2006.

[27] N. S. Balaji, D. Blom, T. R. DeMeester, and J. H. Peters, "Redefining gastroesophageal reflux (GER): detection using multichannel intraluminal impedance in healthy volunteers," Surgical Endoscopy and Other Interventional Techniques, vol. 17, no. 9, pp. 1380-1385, 2003.

[28] D. Sifrim, D. Castell, J. Dent, and P. J. Kahrilas, "Gastrooesophageal reflux monitoring: review and consensus report on detection and definitions of acid, non-acid, and gas reflux," Gut, vol. 53, no. 7, pp. 1024-1031, 2004.

[29] S. S. Shay, L. F. Johnson, and J. E. Richter, "Acid rereflux: a review, emphasizing detection by impedance, manometry, and scintigraphy, and the impact on acid clearing pathophysiology as well as interpreting the $\mathrm{pH}$ record," Digestive Diseases and Sciences, vol. 48, no. 1, pp. 1-9, 2003. 
[30] A. J. Bredenoord, B. L. A. M. Weusten, R. Timmer, J. M. Conchillo, and A. J. P. M. Smout, "Addition of esophageal impedance monitoring to $\mathrm{pH}$ monitoring increases the yield of symptom association analysis in patients off PPI therapy," American Journal of Gastroenterology, vol. 101, no. 3, pp. 453459, 2006

[31] M. F. Vela, L. Camacho-Lobato, R. Srinivasan, R. Tutuian, P. O. Katz, and D. O. Castell, "Simultaneous intraesophageal impedance and $\mathrm{pH}$ measurement of acid and nonacid gastroesophageal reflux: effect of omeprazole," Gastroenterology, vol. 120, no. 7, pp. 1599-1606, 2001.

[32] F. Zerbib, S. Roman, A. Ropert et al., "Esophageal pHimpedance monitoring and symptom analysis in GERD: a study in patients off and on therapy," American Journal of Gastroenterology, vol. 101, no. 9, pp. 1956-1963, 2006.

[33] A. J. Bredenoord, B. L. A. M. Weusten, W. L. Curvers, R. Timmer, and A. J. P. M. Smout, "Determinants of perception of heartburn and regurgitation," Gut, vol. 55, no. 3, pp. 313318, 2006.

[34] D. Sifrim, L. Dupont, K. Blondeau, X. Zhang, J. Tack, and J. Janssens, "Weakly acidic reflux in patients with chronic unexplained cough during 24 hour pressure, $\mathrm{pH}$, and impedance monitoring," Gut, vol. 54, no. 4, pp. 449-454, 2005.

[35] A. P. Tamhankar, J. H. Peters, G. Portale et al., "Omeprazole does not reduce gastroesophageal reflux: new insights using multichannel intraluminal impedance technology," Journal of Gastrointestinal Surgery, vol. 8, no. 7, pp. 890-898, 2004.

[36] R. Tutuian, M. F. Vela, E. G. Hill, I. Mainie, A. Agrawal, and D. O. Castell, "Characteristics of symptomatic reflux episodes on acid suppressive therapy," American Journal of Gastroenterology, vol. 103, no. 5, pp. 1090-1096, 2008.

[37] S. Emerenziani, D. Sifrim, F. I. Habib et al., "Presence of gas in the refluxate enhances reflux perception in non-erosive patients with physiological acid exposure of the oesophagus," Gut, vol. 57, no. 4, pp. 443-447, 2008.

[38] A. J. Wang, M. J. Liang, A. Y. Jiang et al., "Gastroesophageal and laryngopharyngeal reflux detected by 24 -hour combined impedance and $\mathrm{pH}$ monitoring in healthy Chinese volunteers," Journal of Digestive Diseases, vol. 12, no. 3, pp. 173-180, 2011.

[39] J. M. Conchillo, M. P. Schwartz, M. Selimah, M. Samsom, D. Sifrim, and A. J. Smout, "Acid and non-acid reflux patterns in patients with erosive esophagitis and non-erosive reflux disease (NERD): a study using intraluminal impedance monitoring," Digestive Diseases and Sciences, vol. 53, no. 6, pp. 1506-1512, 2008.

[40] A. J. Bredenoord, W. A. Draaisma, B. L. A. M. Weusten, H. G. Gooszen, and A. J. P. M. Smout, "Mechanisms of acid, weakly acidic and gas reflux after anti-reflux surgery," Gut, vol. 57, no. 2, pp. 161-166, 2008.

[41] S. Shay, R. Tutuian, D. Sifrim et al., "Twenty-four hour ambulatory simultaneous impedance and $\mathrm{pH}$ monitoring: a multicenter report of normal values from 60 healthy volunteers," American Journal of Gastroenterology, vol. 99, no. 6, pp. 1037-1043, 2004.

[42] D. Sifrim, R. Holloway, J. Silny et al., "Acid, nonacid, and gas reflux in patients with gastroesophageal reflux disease during ambulatory 24-hour pH-impedance recordings," Gastroenterology, vol. 120, no. 7, pp. 1588-1598, 2001.

[43] F. Zerbib, K. Belhocine, M. Simon et al., "Clinical, but not oesophageal $\mathrm{pH}$-impedance, profiles predict response to proton pump inhibitors in gastro-oesophageal reflux disease," Gut, vol. 61, no. 4, pp. 501-506, 2012.
[44] K. Blondeau, V. Boecxstaens, L. van Oudenhove, R. Farré, G. Boeckxstaens, and J. Tack, "Increasing body weight enhances prevalence and proximal extent of reflux in GERD patients 'on' and 'off' PPI therapy," Neurogastroenterology and Motility, vol. 23, no. 8, pp. 724-e327, 2011.

[45] E. Savarino, P. Zentilin, M. Frazzoni et al., "Characteristics of gastro-esophageal reflux episodes in Barrett's esophagus, erosive esophagitis and healthy volunteers," Neurogastroenterology and Motility, vol. 22, no. 10, pp. 1061-e280, 2010.

[46] P. J. Kahrilas and D. Sifrim, "High-resolution manometry and impedance-pH/manometry: valuable tools in clinical and investigational esophagology," Gastroenterology, vol. 135, no. 3, pp. 756-769, 2008.

[47] D. Sifrim, R. Holloway, J. Silny, J. Tack, A. Lerut, and J. Janssens, "Composition of the postprandial refluxate in patients with gastroesophageal reflux disease," American Journal of Gastroenterology, vol. 96, no. 3, pp. 647-655, 2001.

[48] M. F. Vaezi and J. E. Richter, "Role of acid and duodenogastroesophageal reflux in gastroesophageal reflux disease," Gastroenterology, vol. 111, no. 5, pp. 1192-1199, 1996.

[49] D. O. Francis, M. Goutte, J. C. Slaughter et al., "Traditional reflux parameters and not impedance monitoring predict outcome after fundoplication in extraesophageal reflux," Laryngoscope, vol. 121, no. 9, pp. 1902-1919, 2011.

[50] R. Rosen, P. Levine, J. Lewis, P. Mitchell, and S. Nurko, "Reflux events detected by $\mathrm{pH}-\mathrm{MII}$ do not determine fundoplication outcome," Journal of Pediatric Gastroenterology and Nutrition, vol. 50, no. 3, pp. 251-255, 2010.

[51] M. F. Vaezi, "Reflux monitoring: on or off therapy," American Journal of Gastroenterology, vol. 106, no. 2, pp. 183-185, 2011.

[52] B. N. Arnold, C. M. Dunst, A. B. Gill, T. A. Goers, and L. L. Swanström, "Postoperative impedance-pH testing is unreliable after Nissen fundoplication with or without giant hiatal hernia repair," Journal of Gastrointestinal Surgery, vol. 15, no. 9, pp. 1506-1512, 2011.

[53] D. von Renteln, A. Schmidt, B. Riecken, and K. Caca, "Evaluating outcomes of endoscopic full-thickness plication for gastroesophageal reflux disease (GERD) with impedance monitoring," Surgical Endoscopy and Other Interventional Techniques, vol. 24, no. 5, pp. 1040-1048, 2010.

[54] M. Fox, "Bravo wireless versus catheter $\mathrm{pH}$ monitoring systems," Gut, vol. 55, no. 3, pp. 434-435, 2006.

[55] W. M. Wong, J. Bautista, R. Dekel et al., "Feasibility and tolerability of transnasal/per-oral placement of the wireless $\mathrm{pH}$ capsule vs. traditional 24-h oesophageal $\mathrm{pH}$ monitoring-a randomized trial," Alimentary Pharmacology and Therapeutics, vol. 21, no. 2, pp. 155-163, 2005.

[56] D. Tseng, A. Z. Rizvi, M. B. Fennerty et al., "Forty-eight-hour $\mathrm{pH}$ monitoring increases sensitivity in detecting abnormal esophageal acid exposure," Journal of Gastrointestinal Surgery, vol. 9, no. 8, pp. 1043-1052, 2005.

[57] E. M. Ward, K. R. Devault, E. P. Bouras et al., "Successful oesophageal $\mathrm{pH}$ monitoring with a catheter-free system," Alimentary Pharmacology \& Therapeutics, vol. 19, no. 4, pp. 449-454, 2004.

[58] J. M. Remes-Troche, J. Ibarra-Palomino, R. I. CarmonaSánchez, and M. A. Valdovinos, "Performance, tolerability, and symptoms related to prolonged $\mathrm{pH}$ monitoring using the bravo system in Mexico," American Journal of Gastroenterology, vol. 100, no. 11, pp. 2382-2386, 2005.

[59] Y. C. Lee, H. P. Wang, H. M. Chiu et al., "Patients with functional heartburn are more likely to report retrosternal 
discomfort during wireless $\mathrm{pH}$ monitoring," Gastrointestinal Endoscopy, vol. 62, no. 6, pp. 834-841, 2005.

[60] S. B. des Varannes, F. Mion, P. Ducrotté et al., "Simultaneous recordings of oesophageal acid exposure with conventional $\mathrm{pH}$ monitoring and a wireless system (Bravo)," Gut, vol. 54, no. 12, pp. 1682-1686, 2005.

[61] M. F. Vaezi, “Should we bravo?” Gastroenterology, vol. 130, no. 7, pp. 2238-2239, 2006.

[62] J. E. Pandolfino, J. E. Richter, T. Ours, J. M. Guardino, J. Chapman, and P. J. Kahrilas, "Ambulatory esophageal pH monitoring using a wireless system," American Journal of Gastroenterology, vol. 98, no. 4, pp. 740-749, 2003.

[63] M. Fox, "Bravo wireless versus catheter $\mathrm{pH}$ monitoring systems," Gut, vol. 55, no. 3, pp. 434-435, 2006.

[64] J. E. Pandolfino, Q. Zhang, M. A. Schreiner, S. Ghosh, M. P. Roth, and P. J. Kahrilas, "Acid reflux event detection using the Bravo wireless versus the Slimline catheter $\mathrm{pH}$ systems: why are the numbers so different?" Gut, vol. 54, no. 12, pp. 16871692, 2005.

[65] D. Tseng, A. Z. Rizvi, M. B. Fennerty et al., "Forty-eight-hour $\mathrm{pH}$ monitoring increases sensitivity in detecting abnormal esophageal acid exposure," Journal of Gastrointestinal Surgery, vol. 9, no. 8, pp. 1043-1052, 2005.

[66] R. Sweis, M. Fox, A. Anggiansah, and T. Wong, "Prolonged, wireless $\mathrm{pH}$-studies have a high diagnostic yield in patients with reflux symptoms and negative 24 -h catheter-based $\mathrm{pH}-$ studies," Neurogastroenterology and Motility, vol. 23, no. 5, pp. 419-426, 2011.

[67] C. L. Chen and C. H. Yi, "Utility of esophageal impedance in identifying dysmotility in patients with erosive esophagitis," Diseases of the Esophagus, vol. 21, no. 6, pp. 539-543, 2008.

[68] W. Blonski, A. Hila, V. Jain, J. Freeman, M. Vela, and D. O. Castell, "Impedance manometry with viscous test solution increases detection of esophageal function defects compared to liquid swallows," Scandinavian Journal of Gastroenterology, vol. 42, no. 8, pp. 917-922, 2007.

[69] B. Basseri, M. Pimentel, O. A. Shaye, K. Low, E. E. Soffer, and J. L. Conklin, "Apple sauce improves detection of esophageal motor dysfunction during high-resolution manometry evaluation of dysphagia," Digestive Diseases and Sciences, vol. 56, no. 6, pp. 1723-1728, 2011.

[70] C. L. Chen, C. H. Yi, A. S. Chou, and T. T. Liu, "Esophageal solid bolus transit: studies using combined multichannel intraluminal impedance and manometry in healthy volunteers," Diseases of the Esophagus. In press.

[71] H. N. Nguyen, G. R. S. Domingues, and F. Lammert, "Technological insights: combined impedance manometry for esophageal motility testing-current results and further implications," World Journal of Gastroenterology, vol. 12, no. 39, pp. 6266-6273, 2006.

[72] R. Tutuian and D. O. Castell, "Combined multichannel intraluminal impedance and manometry clarifies esophageal function abnormalities: study in 350 patients," American Journal of Gastroenterology, vol. 99, no. 6, pp. 1011-1019, 2004.

[73] H. N. Nguyen, G. R. Domingues, R. Winograd, F. Lammert, J. Silny, and S. Matern, "Impedance characteristics of esophageal motor function in achalasia," Diseases of the Esophagus, vol. 17, no. 1, pp. 44-50, 2004.

[74] J. M. Conchillo, N. Q. Nguyen, M. Samsom, R. H. Holloway, and A. J. P. M. Smout, "Multichannel intraluminal impedance monitoring in the evaluation of patients with non-obstructive dysphagia," American Journal of Gastroenterology, vol. 100, no. 12, pp. 2624-2632, 2005.
[75] R. Tutuian, M. F. Vela, S. S. Shay, and D. O. Castell, "Multichannel intraluminal impedance in esophageal function testing and gastroesophageal reflux monitoring," Journal of Clinical Gastroenterology, vol. 37, no. 3, pp. 206-215, 2003.

[76] B. F. Kessing, A. J. Smout, and A. J. Bredenoord, "Clinical applications of esophageal impedance monitoring and highresolution manometry," Current Gastroenterology Reports, vol. 14, no. 3, pp. 197-205, 2012.

[77] Y. K. Cho, M. G. Choi, S. N. Oh et al., "Comparison of bolus transit patterns identified by esophageal impedance to barium esophagram in patients with dysphagia," Diseases of the Esophagus, vol. 25, no. 1, pp. 17-25, 2012.

[78] M. Montenovo, R. P. Tatum, E. Figueredo et al., "Does combined multichannel intraluminal esophageal impedance and manometry predict postoperative dysphagia after laparoscopic Nissen fundoplication?" Diseases of the Esophagus, vol. 22, no. 8, pp. 656-663, 2009.

[79] C. L. Chen and C. H. Yi, "Clinical correlates of dysphagia to oesophageal dysmotility: studies using combined manometry and impedance," Neurogastroenterology and Motility, vol. 20, no. 6, pp. 611-617, 2008.

[80] A. Bogte, A. J. Bredenoord, J. Oors, P. D. Siersema, and A. J. Smout, "Relationship between esophageal contraction patterns and clearance of swallowed liquid and solid boluses in healthy controls and patients with dysphagia," Neurogastroenterology and Motility, vol. 24, no. 8, pp. e364-e372, 2012.

[81] J. E. Richter, “Oesophageal motility disorders," The Lancet, vol. 358, no. 9284, pp. 823-828, 2001.

[82] A. J. Bredenoord, M. Fox, P. J. Kahrilas et al., "Chicago classification criteria of esophageal motility disorders defined in high resolution esophageal pressure topography," Neurogastroenterology and Motility, vol. 24, supplement 1, pp. 57-65, 2012.

[83] J. E. Pandolfino, M. A. Kwiatek, T. Nealis, W. Bulsiewicz, J. Post, and P. J. Kahrilas, "Achalasia: a new clinically relevant classification by high-resolution manometry," Gastroenterology, vol. 135, no. 5, pp. 1526-1533, 2008.

[84] R. Salvador, M. Costantini, G. Zaninotto et al., "The preoperative manometric pattern predicts the outcome of surgical treatment for esophageal achalasia," Journal of Gastrointestinal Surgery, vol. 14, no. 11, pp. 1635-1645, 2010.

[85] T. H. Lee, J. S. Lee, and W. J. Kim, "High resolution impedance manometric findings in dysphagia of Huntington's disease," World Journal of Gastroenterology, vol. 18, no. 14, pp. 16951699, 2012.

[86] K. W. Jung, H. Y. Jung, Y. Romero, D. Katzka, and J. A. Murray, "Impact of display alternatives in the determination of bolus handling: a study using high-resolution manometry with impedance," The American Journal of Gastroenterology, vol. 106, no. 10, pp. 1854-1856, 2011.

[87] M. Hoshino, A. Sundaram, A. Juhasz et al., "High-resolution impedance manometry findings in patients with nutcracker esophagus," Journal of Gastroenterology and Hepatology, vol. 27, no. 3, pp. 592-597, 2012.

[88] B. F. Kessing, F. Govaert, A. A. Masclee, and J. M. Conchillo, "Impedance measurements and high-resolution manometry help to better define rumination episodes," Scandinavian Journal of Gastroenterology, vol. 46, no. 11, pp. 1310-1315, 2011.

[89] W. J. Bulsiewicz, P. J. Kahrilas, M. A. Kwiatek, S. K. Ghosh, A. Meek, and J. E. Pandolfino, "Esophageal pressure topography criteria indicative of incomplete bolus clearance: a study using 
high-resolution impedance manometry," American Journal of Gastroenterology, vol. 104, no. 11, pp. 2721-2728, 2009.

[90] S. Roman, Z. Lin, M. A. Kwiatek, J. E. Pandolfino, and P. J. Kahrilas, "Weak peristalsis in esophageal pressure topography: classification and association with dysphagia," American Journal of Gastroenterology, vol. 106, no. 2, pp. 349-356, 2011.

[91] C. L. Chen and C. H. Yi, "Clinical correlates of dysphagia to oesophageal dysmotility: studies using combined manometry and impedance," Neurogastroenterology and Motility, vol. 20, no. 6, pp. 611-617, 2008.

[92] A. Lazarescu, G. Karamanolis, L. Aprile, R. B. De Oliveira, R. Dantas, and D. Sifrim, "Perception of dysphagia: lack of correlation with objective measurements of esophageal function," Neurogastroenterology and Motility, vol. 22, no. 12, pp. 1292-1297, 2010.

[93] J. M. Conchillo, M. Selimah, A. J. Bredenoord, M. Samsom, and A. J. P. M. Smout, "Assessment of oesophageal emptying in achalasia patients by intraluminal impedance monitoring," Neurogastroenterology and Motility, vol. 18, no. 11, pp. 971977, 2006.

[94] J. C. Myers, G. G. Jamieson, T. Sullivan, and J. Dent, "Dysphagia and gastroesophageal junction resistance to flow following partial and total fundoplication," Journal of Gastrointestinal Surgery, vol. 16, no. 3, pp. 475-485, 2012.

[95] D. Ang, T. L. Ang, E. K. Teo et al., "Is impedance $\mathrm{pH}$ monitoring superior to the conventional $24-\mathrm{h} \mathrm{pH}$ meter in the evaluation of patients with laryngorespiratory symptoms suspected to be due to gastroesophageal reflux disease?" Journal of Digestive Diseases, vol. 12, no. 5, pp. 341-348, 2011.

[96] D. Sifrim and F. Zerbib, "Diagnosis and management of patients with reflux symptoms refractory to proton pump inhibitors," Gut, vol. 61, no. 9, pp. 1340-1354, 2012.

[97] D. Nehra, "Bile in the esophagus-model for a bile acid biosensor," Journal of Gastrointestinal Surgery, vol. 14, supplement 1, pp. S6-S8, 2010.

[98] T. Ativanichayaphong, S. J. Tang, J. Wang et al., "An implantable, wireless and batteryless impedance sensor capsule for detecting acidic and non-acidic reflux [abstract]," Digestive Disease Week, San Diego, Calif, USA, 2008.

[99] X. Gao, D. C. Sadowski, and M. P. Mintchev, "Intraluminal ultrasonic probe for volumetric monitoring of liquid gastroesophageal reflux," Physiological Measurement, vol. 33, no. 3, pp. 487-501, 2012. 


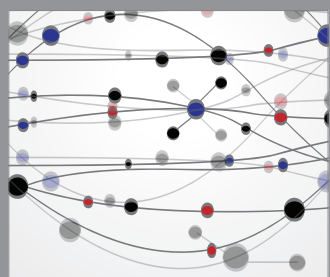

The Scientific World Journal
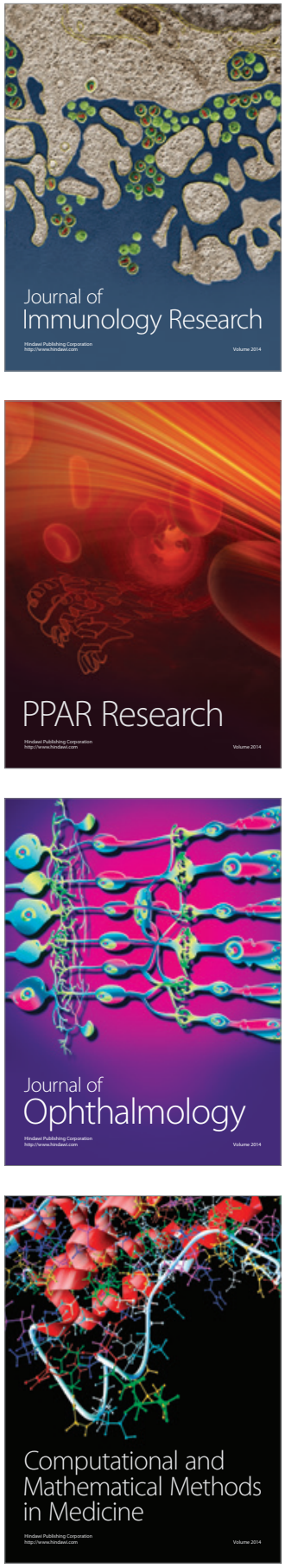

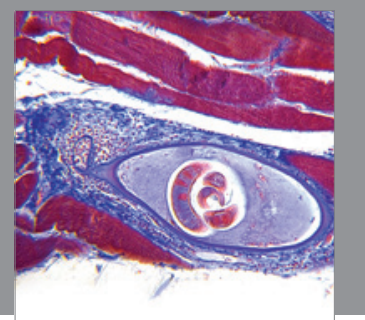

Gastroenterology

Research and Practice
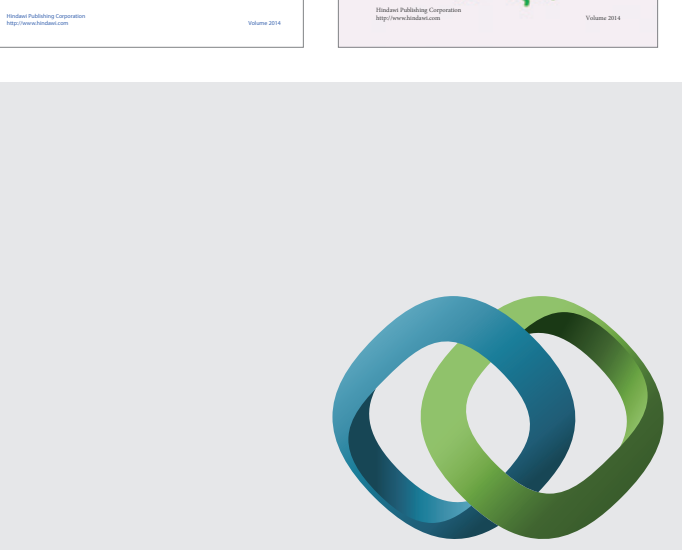

\section{Hindawi}

Submit your manuscripts at

http://www.hindawi.com
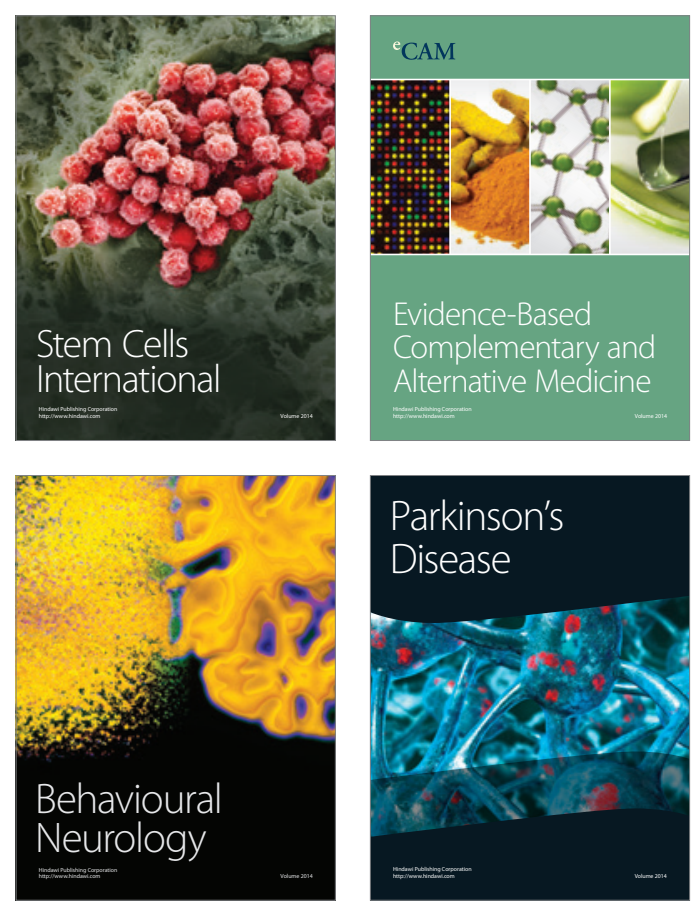

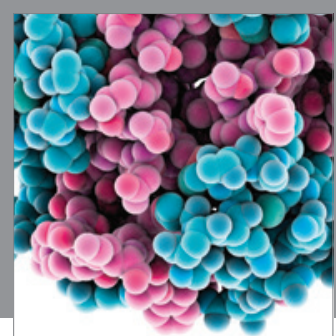

Journal of
Diabetes Research

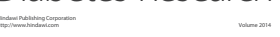

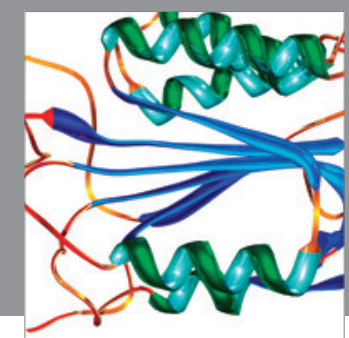

Disease Markers
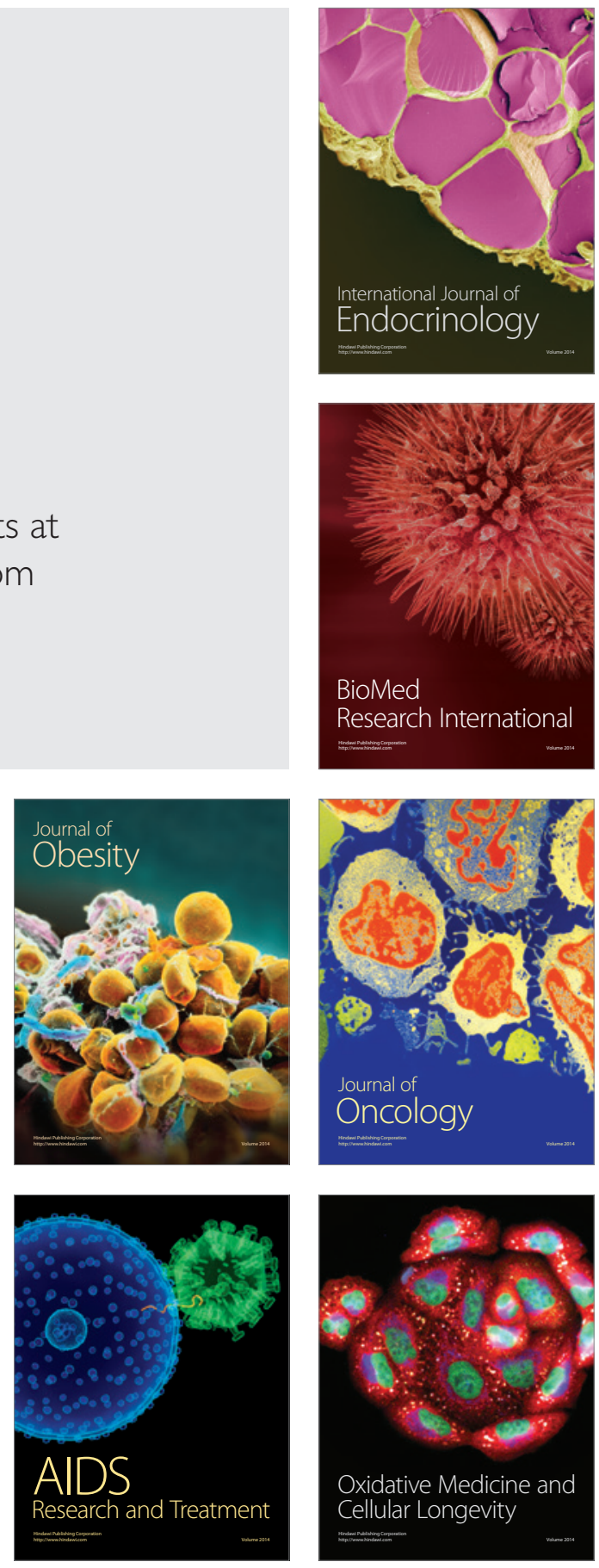